\title{
Lean Thinking, Logistic and Ergonomics: Synergetic Triad to Prepare Shop Floor Work Systems to Face Pandemic Situations
}

\author{
Tiago Afonso ${ }^{1} \cdot$ Anabela C. Alves $^{1,2} \cdot$ Paula Carneiro ${ }^{1,2}$
}

Received: 18 January 2021 / Accepted: 12 August 2021 / Published online: 13 September 2021

(c) Global Institute of Flexible Systems Management 2021

\begin{abstract}
Health crisis caused by COVID-19 had a significant impact on the activities and performance of companies worldwide, namely in industries. In this context, the adaptation of companies to the markets and to the new demands of consumers, readapt to strategies, processes, products, and approaches to the market, become paramount. In the case of companies, some changes in the shop floor work systems become essential, to provide competitive advantages in post-pandemic business scenarios, developing new approaches to increase the efficiency, agility and resilience of operations, always tends to account the Lean Thinking approach and its principles. Thus, the purpose of this article is to show that through Lean philosophy, Lean Logistics and ergonomic tools, one can change the manufacturing space and reduce human interaction in a post-pandemic scenario. In addition, through these three approaches associated with Industry 4.0, this article shows a project in a real case study in an automotive company, to integrate Automated Guided Vehicles (AGV) among other technologies. The study of AGV integration used a simulation model designed in Simio. This project could allow to significantly reduce the ergonomic risks, energy consumption and associated $\mathrm{CO} 2$ emissions, and the flow of materials within the organization. The costs could be reduced by $14 \%$ in the first year of implementing AGVs and $40 \%$ in the second year after implementation. Introducing autonomous AGV will reduce the need of interaction among employees which is fundamental for healthy environments in pandemic context.
\end{abstract}

Keywords Lean thinking $\cdot$ Lean logistics $\cdot$ Ergonomics $\cdot$ Industry 4.0

\section{Introduction}

The year 2020 was marked by a hitherto unknown virus. The pandemic generated an unprecedented economic crisis in a short time. COVID-19 pandemic created a huge disturbance worldwide and in a global one reaching the most developed and in developing countries. The spontaneous interruption in the demand for some goods and services, globally

Anabela C. Alves

anabela@dps.uminho.pt

Tiago Afonso

Tiagoanuel@gmail.com

Paula Carneiro

pcarneiro@dps.uminho.pt

1 Department of Production and Systems, School of Engineering of University of Minho, Campus of Azurém, 4800-058 Guimarães, Portugal

2 ALGORITMI Centre, Department of Production and Systems, School of Engineering, Guimarães, Portugal interrupted the supply chain and its standard operation. In addition, along with the increased demand for pharmaceutical and medicinal products, production and consumer supply chains have been severely disrupted (Deshumukh \& Haleem, 2020; Flynn et al., 2020; Ivanov \& Dolgui, 2020).

In Portugal, for example, the crisis triggered by the new coronavirus interrupted the improvement trends registered in the Portuguese economy, knowing that recent European Commission forecasts suggest that the Portuguese GDP will fall 6.8\% in 2020 (INEE, 2020). In 2019, the value of sales of products and the provision of industrial services registered 94.1 billion euros, representing an increase of $2.7 \%$ compared to the previous year, representing an increase of $7.1 \%$ in 2018, which alone proves the positive evolution of the sector in the Portuguese economy. The top five divisions (pharma, agriculture machinery, capital goods, etc.) grew $4.9 \%$ (more $12.4 \%$ in 2018), representing $45.5 \%$ of the total manufacturing industries (INEE, 2020).

In an open economy like the Portuguese, the negative effects of pandemic COVID-19, which forced the population 
to be confined to their homes between March and May, causing economic activity to close almost entirely, and subsequently, a lack of confidence with the adoption of drastic safety measures, was felt in the main sectors of the economy and the lives of Portuguese companies and their employees (Coimbra, 2009). Thus, in Portugal, in the short term, a severe impact of the COVID-19 crisis is expected on the economic activity of the sectors that contribute the most to the national economy, namely industry, with a negative impact on $6 \%$ of the national GDP, $8 \%$ with regard to the manufacturing industry and $16 \%$ of national exports of tradable goods, fundamental for an open economy like Portugal (AICEP, 2020).

This crisis proves the dependence of the European Union member countries on the great world powers at the economic level, with a great impact on world GDP, in this case China and the United States. Global stock exchanges have fallen about $30 \%$ since the beginning of the year in most of the world's richest countries (Dw, 2020).

COVID-19 virus is considered to have origin in the city of Wuhan, belonging to the province of Hubei, in December 2019, being a region with a very significant impact on global supply chains, China being the second power in the world. The outbreak of the COVID-19 crisis has an impact on industries worldwide, reinforcing the importance of new technologies, the flexibility of companies to adapt to new market demands. Hence, emerge the need to rigorously study new opportunities and to further increase interest in value chains impacted by the health crisis.

Thus, in a context of crisis, opportunities also arise. The world finds new measures and adapt to continue the development of economies, associating and providing innovation and outstanding research. To resort to the use of new technologies, new strategies and new processes, companies can continue their activities and respond to the market. In postCOVID-19, countries will try to turn inwards by producing at the national level. To support such activities, governments prepare some relief package for assistance for companies to bypass this crisis. For example, Indian government prepared a Lean Manufacturing Competitiveness Scheme (LMCS) (Deshumukh \& Haleem, 2020). With this, they expect that their companies, mainly the most fragile such as micro-, small and medium companies improve the quality of their products reducing the costs.

This means that Lean Thinking (Womack \& Jones, 1996) could be, more than ever, an ally to face such crisis. Moreover, if well established in the companies' mindset and culture, it will be the trigger for the integration of Industry 4.0 technologies that emerged from the concept of Industry 4.0 (Bittencourt et al., 2019, 2020). In this way, it is essential to take advantage of the infrastructure associated with new autonomous technologies associated with Industry 4.0.
In this sense, this paper reports the project undertaken to incorporate new technologies in the transport and handling of loads, to eliminate wastes and improve the safety and ergonomic conditions of the shop floor workers within an automotive company. In this project, the authors proposed the use of the synergy of ergonomic methods, Lean principles applied to logistic, and new technologies as AGV. The project started in the pre-COVID-19 period, being interrupted by it and the authors were forced to think in what way the planned proposals could be adapted to the pandemic situation. The research questions that guided the project were:

1. What were the wastes and the main root causes?

2. What is the ergonomic risk level of the tasks performed by the logistics and production workers?

3. How to avoid and/or reduce the interaction between the workers?

4. Are Lean Thinking, Logistic and Ergonomics suitable to prepare shop floor work systems to face pandemic situations?

This paper is divided in six sections. The first section refers to the introduction. A brief literature review was made in the second section. The third section presents the materials and methodology used in this paper. The fourth section addresses the study of the real case, with the characterization of the company, critical analysis and proposals for improvement. The fifth section explains the management implications. Finally, the main remarks covered in the paper are discussed in the last section.

\section{Brief Literature Review}

This section presents, first, a brief review of the literature related to the synergistic triad, Lean manufacturing, Lean logistics, and the principles of ergonomics. In a second time, we address the interconnection between Lean and Industry 4.0, and finally the importance and the need for automation in industries, which was accentuated in the context of the health crisis of COVID-19.

\section{Lean Manufacturing, Lean Logistics and Ergonomics}

Lean Production is a management methodology that allows companies to be competitive and able to meet market demands. It originated in the Toyota Production System (TPS) (Mattos et al., 2016), being a production organization model focused on the customer who seeks the elimination of waste. Waste are the activities that do not add value to the product in the point of view of the client and that he/ she is not willing to pay for, and the timely delivery of the 
products, bringing many benefits to the companies (Womack et al., 1990).

This methodology has as main objective to do more with less, that is, less time, less space, less human effort, less equipment, and more efficiency and greater understanding of the client's needs (Womack et al., 1990). At the same time, TPS provides “... a work environment that is safe physically, emotionally and professionally for every employee" (Spear \& Bowen, 1999).

These authors define Lean Production as an innovative production system that combines the advantages of the artisanal production system with the mass production system, avoiding the high cost of the first and the rigidity of the second. When analyzing the processes in the search for identification and elimination of waste with a focus on continuous improvement, the importance of understanding three concepts must be considered: muda (waste), mura (irregularity, variability) and muri (overload, overburden). These three concepts relate to the 3M's model, which refers to the types of waste found in an organization. Muda means waste, referred above. There are seven types of waste: transports; inventory; motion; waiting; overproduction; over-processing and defects (Ohno, 1988). In addition, some authors, namely, Liker (2004) discusses the untapped human potential. Mura refers to the variation or variability observed along the value chain. Muri means overload and happens when workers or machines operate above their capacity (Liker, 2004).

Lean Thinking philosophy emerged as a need to respond to the companies' queries that intended to implement TPS, as referred by Womack and Jones (1996). It consists in creating a continuous flow of value delivery to the customer, reducing the loss of organizational resources as much as possible. The five basic principles of this philosophy defined by the authors are: (1) Value; (2) Value Stream; (3) Flow; (4) Pull production; (5) Pursuit of perfection (Womack \& Jones, 1996).

The application of Lean principles to logistics is called Lean Logistics where concepts such as milk run, supermarkets and borderline are studied to better supply the production system. The design and operation of the milk run routes are of great importance for the creation of flow (Coimbra, 2009). These concepts are fundamental to increase the efficiency of the internal value chain within organizations. At the same time, logistic operations imply load transport and handling performed, most of times, by human operators. This means that the best working conditions must be assured. In this way, it is possible to demonstrate efficient ways to improve jobs, aiming at the well-being of operators, providing the overall performance within organizations (Mattos et al., 2016).

Lean Production aims to maximize value and reduce waste through different tools and specific techniques for diagnosis and improvement of processes, which should be linked also to improve working conditions and safety of employees (Arezes et al., 2015). Muri and mura are root causes of waste that could be reduced by improving work and safety conditions of the workers (Alves et al., 2019a, 2019b; Brito et al., 2019). Hence, there is an added importance in reducing operators' effort. Thus, the mura and the muri should be the focus and concern of companies so that people have better working conditions to perform well and thus eliminate the symptoms of the muda (Melo et al., 2020).

According to the International Ergonomics Association (IEA), ergonomics, also known as human factors, is a scientific discipline that studies Human interactions with other elements of the system, with the aim of improving human well-being and overall performance of the system (IEA, 2021). For example, the conditions under which certain tasks are performed, as well as their characteristics and requirements can cause Musculoskeletal Disorders (MSD) to workers over time. When MSD are originated by work, or aggravated by it, they are called Work-related Musculoskeletal Disorders (WMSD). The main risk factors associated with WMSD are repetitive tasks, tasks that involve the application of force, and the adoption of inadequate postures (Barroso et al., 2006).

\section{Lean Interrelations with Industry 4.0}

Since TPS roots, the technologies and how they could help the worker and improve processes have been a concern, as continuously referred by Liker (2006): "adopt and adapt technology that fits and supports people and processes" (Liker \& Morgan, 2006) or even, earlier, Monden (1998): “In short, robots, like any other kind of technology must remain the tool of men and not the other way around!" (Monden, 1998). Jidoka or autonomation, one of TPS pillars is based on the concept of low-cost automation. Nevertheless, autonomation is not the same as automation. Autonomation means automation with human element what reinforces the role of people in identifying automation needs and in controlling the way automation is done and is working. This means that when people needs to stop the line, they have this control. The same is true for the machines, they have to be "smart" enough to stop when defects or others problems (e.g., lack of materials) are detected.

Thus, TPS mentors were in the first line in recognizing the value of intelligent automation. By sure, automation in productive environments is a determining factor for companies that work with their goals in terms of process performance and productivity levels (Waschull et al., 2020). It is possible to find different forms of automation, depending on the processes in question and the types of variables to control, either in the control of a process variable associated with a transformation operation, or in the movement of materials, that is, automation is inextricably linked to the 
industry as we know it today. In fact, most of the industrialized processes required, nowadays, a high degree of automation to make its activity viable (Waschull et al., 2020).

Automation could be a strong ally of Lean manufacturing and a strategic tool for process reorganization and waste reduction (De Oliveira et al., 2017). To implement Lean Production and after a process of wastes elimination and normalization, it is also essential to implement automation, whether in production processes, to improve the efficiency of production processes, as well as in logistics processes, to improve an organization's internal value chain.

Industrial automation is constantly evolving. Hence, technological innovation requires a constant effort to integrate it with existing technologies to respond to the needs of organizations, in very specific processes, and they must also be flexible and easy to be programmed (Waschull et al., 2020). Integrated in the concept of Industry 4.0 (I4.0), it will have an impact more profound than just digitization, involving a profound form of innovation based on the combination of multiple technologies, which will force companies to rethink how they manage their processes and businesses, how they position themselves in the supply chain, how they promote the development of new products and introduce them to the market (Bittencourt et al., 2019).

The role of Lean in the implementation process of Industry 4.0 stands out, highlighting Lean concepts such as work standardization, organization and transparency as support for the implementation of solutions linked to I4.0. In this way, Lean can be used as a basis to build an I4.0 implementation, becoming a trigger and a facilitator in this implementation process (Bittencourt et al., 2020). According to Mayr et al. (2018), Lean and I4.0 aim at the same goals to improve productivity, and in this way, I4.0 can support Lean methodologies (Mayr et al., 2018).

The concept of I4.0 can be interpreted as a strategy to increase competitiveness in the future scenario. This focuses on optimizing the value chain due to dynamic and autonomously controlled production. In this case, it facilitates fundamental improvements in the industrial processes involved in manufacturing, use of materials, supply chain and life cycle management (Abdirad \& Krishnan, 2020; Kagermann et al., 2013). There are smart factories that are starting to emerge and address a new productive approach aided by all other technologies brought by I4.0 (Oztemel \& Gursev, 2020). Achieving the paradigm shift required for the delivery of I4.0 is a long-term project and requires a gradual process. Through this process, it will be essential to ensure that the values of the current manufacturing systems are preserved (Bittencourt et al., 2019).

Industry 4.0 and Lean can coexist and support each other and commit to overcoming existing barriers to implement lean. To combine Lean and Industry 4.0, existing literature has expressed terms such as lean 4.0, lean automation, smart lean manufacturing and I4.0 (Valamede \& Akkari, 2020). As elaborated, most authors approve the general compatibility of Lean and Industry 4.0 (Mrugalska \& Wyrwicka, 2017; Tortorella \& Fettermann, 2018; Tortorella et al., 2019). This perspective can be attributed to similarities on goals such as reducing complexity, central pillars and lean principles as common ground (Mayr et al., 2018).

Industry 4.0 can improve Lean, not only by eliminating waste associated with processes, but also emphasizing the ability to improve the flexibility of modern Lean Production Systems, and consequently, contributes to dealing with the limitations of Lean. In addition, Industry 4.0 is promising to deal with a constant change in market demand, impacting Lean, and eventually provides greater flexibility as Industry 4.0 helps to cope with the increasing complexity of markets (Mayr et al., 2018).

At the same time, automation solutions using Industry 4.0 technologies could bring an ergonomic and safer environment for the workers (Brito et al., 2019). Particularly, Automated Guided Vehicles (AGV), exoskeletons, robots, virtual and augmented reality, and digital twins among others could be very useful to reduce workload, risk, effort, repetitive and monotonous tasks (Brito et al., 2019). Some authors are discussing the concept of Operator 4.0, using the technology to aid and empower the worker (Kaasinen et al., 2020; Romero et al., 2016; Romero et al. 2020; Romero et al., 2016).

Automation in the context of the crisis of COVID-19 becomes valid and essential for processes within industries. Some processes, whether productive or logistical, need a great deal of interaction and intervention on the part of workers. However, it is up to organizations to introduce and improve some processes, which at times is still archaic, to limit physical contact between workers. Technologies as the ones brought by Industry 4.0 such as virtual reality, 3D simulation, digital twins, e-Kanban, RFID, real-time visualization, cyber-physical systems, and cobots are helpful (Freitas et al., 2017; Kolberg \& Zühlke, 2015; Malik \& Brem, 2021).

It is important to bear in mind that the success of the introduction of I4.0 technologies depends on several factors, including usability, selective provision of information, user acceptance, consideration of ethics, legal and social impacts and profitability. Therefore, the use of I4.0 tools must be well considered and evaluated in relation to process improvements (Mayr et al., 2018).

\section{Materials and Methods}

The project described in this paper was developed in a company's work environment. The researcher had the opportunity to be part of the company staff, researching and working there for a time-frame of 7 months. The researcher initiated various cycles of action and research to 
develop the proposals that answer to the questions raised in the introduction section. The five phases of the actionresearch methodology were implemented: (1) diagnosis and problem definition; (2) actions planning; (3) implementing; (4) measure and evaluate; and (5) learning specification (O'Brien, 1998).

Action-research methodology is problem-solving oriented, thus the concern was to identify the problems for the first phase and answer to the first two questions:

1) What were the problems and wastes and the main root causes on the shop floor?

2) What was the ergonomic risk level of the tasks performed by the logistics and production workers?

To answer to those questions several methods and techniques were used, namely observations, dialogues, documental analysis, time study, work sampling, Value Stream Mapping (VSM), warehouse process mapping using Business Process Modelling Notation (BPMN), Sue Rodgers ergonomic analysis, risk assessment in manual material handling tasks, applying the NIOSH equation, and posture evaluation, applying Ovako Working Posture Analysis System (OWAS) methodology.

In the second phase, some actions were planned to eliminate such wastes, being proposed 5S, Standard Work, visual management, layout reconfiguration, and AGV introduction. Those were studied having also in mind the third question:

3) How to avoid and/or reduce the interaction between the workers?

In the third phase, some of these tools were implemented. The fourth phase implied the evaluation of the proposals and for this it simulation and Analytic Hierarchy Process (AHP) was used, among others. The fifth phase implied the learning specification and the proposals for future work to start new cycles of action-research. Finalizing this cycle, the authors wanted to answer to the fourth question:

4) Are Lean Thinking, Logistic and Ergonomics suitable to prepare shop floor work systems to face pandemic situations?

\section{Company Characterization, Critical Analysis and Improvement Proposals}

This section presents the characterization and diagnosis of the company shop floor after a deep critical analysis. Then, the improvement proposals focusing the logistic processes are presented, with the analysis of the technological needs associated with the project, its results, and its relevance in the context of the pandemic COVID-19.

\section{Shop Floor Characterization and Problems Identification}

The company where the project was developed is a multinational company of metal parts for automobile industry. It is a "dirt" company working "heavy" and long parts, e.g., stamped pieces. In it works a significant number of employees. The factory is divided into sections called autonomous production unit (APU).

This study concerns an autonomous production unit (APU), where two large presses are located, called transfer presses. In this factory, two main production processes can be found: (1) stamping and (2) welding. In this APU, the presses Machine 1 (M1) and Machine 2 (M2) that stamp medium and large pieces were the concern. In this specific section of the factory, there were several problems associated both in terms of internal logistics, ergonomics, and production and in relation to the organization of the physical space of the autonomous production unit explained in the next sections.

\section{Logistic Problems and Wastes Associated}

In the case of machines, these had a lot of stoppages due to the delay of the logistics trains in collecting the full containers and leaving the empty containers close to the machines. This happened due to the lack of material allocation at the scheduled time and the delay of the forklifts, both to perform, sometimes, the same tasks that the train, as for the allocation of formats (raw materials) on the machines.

For about 2 years, the company has been trying to implement milk runs to improve the physical flow of materials, in all APU. With this, the company intended to improve the company's internal value flow, trying to use a just-in-time culture way of placing the desired material on the edges of the line or together with the machines, at the right time and in the appropriate quantity. This attempt was made as part of a continuous improvement project, based on Lean production and with the objective of reducing the waste associated with the supply and performance of the machines.

However, the incorporation of the milk run, whose function is to allocate the empty containers on the edge of the machines, so that the production workers place the parts, whether final or in the process of manufacture, had caused some problems, not only at the level of internal logistics, but also in a generic and ergonomic point of view. Generically, the situation of APU study leaded to high time of stoppages of the machine, high time of setups, excessive movements and motion, high materials transport, and many other problems, derived of the need for logistic trains or forklifts arrived in time for the machines. 


\section{Ergonomic Risk}

Associated with the situation described above, there were some ergonomic issues. Those were derived from the forces exerted by the logistics and production workers in the subtasks of pushing/pulling the filled containers, where the packaging loads were heavy. This difficult the handling of containers located on the rolling support by both workers. In addition, there was no standard for picking up parts. The lack of a standard forced the production workers to pick up a high number of parts before placing them in empty containers. This situation in itself represented a concrete cause of the ergonomic problems associated with the machine workers' tasks, as well as inadequate postures. These affected the performance of both tasks. It is noteworthy to refer that when the containers were full with steel or aluminum parts, its weight becomes significant and could reached $500-850 \mathrm{~kg}$. This difficult the task to maneuver these localized packages in a rolling stand, reaching up to $1200 \mathrm{~kg}$. In this case, a forklift was used to collect the container.

Considering this situation, it was realized that the production and logistics workers could work under high WMSD risk. In this way, a detailed ergonomic study was carried out. In the first stage, an ergonomic analysis using the Sue Rodgers method was performed to verify which parts of the body were affected by the tasks. With this method, it was measured the effort, the duration, and the frequency required by each part of the body when performing a task, on a scale of 1-3. From these parameters, a prediction of muscle fatigue was made. For the detection of the existence of ergonomic risk in manual handling of loads (MHL) the detection criterion was estimated when loads greater than $3 \mathrm{~kg}$ were handled, in this case, there was a risk ergonomic. After performing the ergonomic analysis, it was found that the most affected areas of the body when performing tasks, were the shoulder and lumbar areas. After this first ergonomic analysis, it became necessary to assess the ergonomic risk associated with the tasks.

The method used for the ergonomic evaluation in relation to MHL was the NIOSH equation. This equation allows to calculate the recommended limit weight (RLW) and the lifting index (relates the actually weight handled with the RLW).

The other methodology, the OWAS methodology, was used to assess the adopted postures, through four levels of risk. In this ergonomic evaluation, it was intended to study the inadequate postures of the production and logistics workers. It was necessary to describe the sub-tasks performed by the workers and the frequency of these sub-tasks. From these, the observed postures were selected and analyzed according to the OWAS method. The identification of the risk levels depends on the duration times of the postures, which are classified as, level 1 (normal posture, which requires care, except in exceptional cases), level 2 (posture that must be checked during the next review), level 3: posture that deserves attention in the short term, and finally, level 4 (posture that deserves immediate attention).

Table 1 synthetizes all the ergonomic problems found, the methods used, the risk level and the result. It was found that the tasks performed by both workers lead to high ergonomic risks. It is important to refer that the company use some tools (e.g., informatics software) that employ the ergonomic methods referred but, due to the confidentiality, those cannot be detailed.

\section{Synthesis of the Main Root Causes, Wastes and Consequences}

This section presents the main root causes of the problems identified, the wastes and consequences of them. It was found that the organization of the company's stamping lines, provided waste of waiting, handling and transportation of materials. The path of the logistic train and organization of the forklift's tasks led to these wastes. Figure 1 presents the synthesis of those problems identified as well as their causes, wastes type and consequences. Due to the paper space limitation and it focus, some of those problems were not detailed.

Finally, to the existent problems, it was added the health crisis of COVID-19. This provided an important opportunity for the introduction of a specific automated logistic system. Some of the types of specific problems encountered
Table 1 Ergonomic problems, methods used, risk level and result

\begin{tabular}{llll}
\hline Ergonomic problem & Methods used & Risk level & Result \\
\hline $\begin{array}{l}\text { High forces and wrong } \\
\text { postures for production } \\
\text { worker }\end{array}$ & OWAS & 3 & Medium-high risk \\
$\begin{array}{l}\text { High forces and wrong } \\
\text { postures for logistic } \\
\text { worker }\end{array}$ & OWAS & 4 & High risk \\
$\begin{array}{l}\text { Manual lifting load } \\
\text { Heavy workload }\end{array}$ & NIOSH & PLR value above 2 & High risk \\
\hline
\end{tabular}




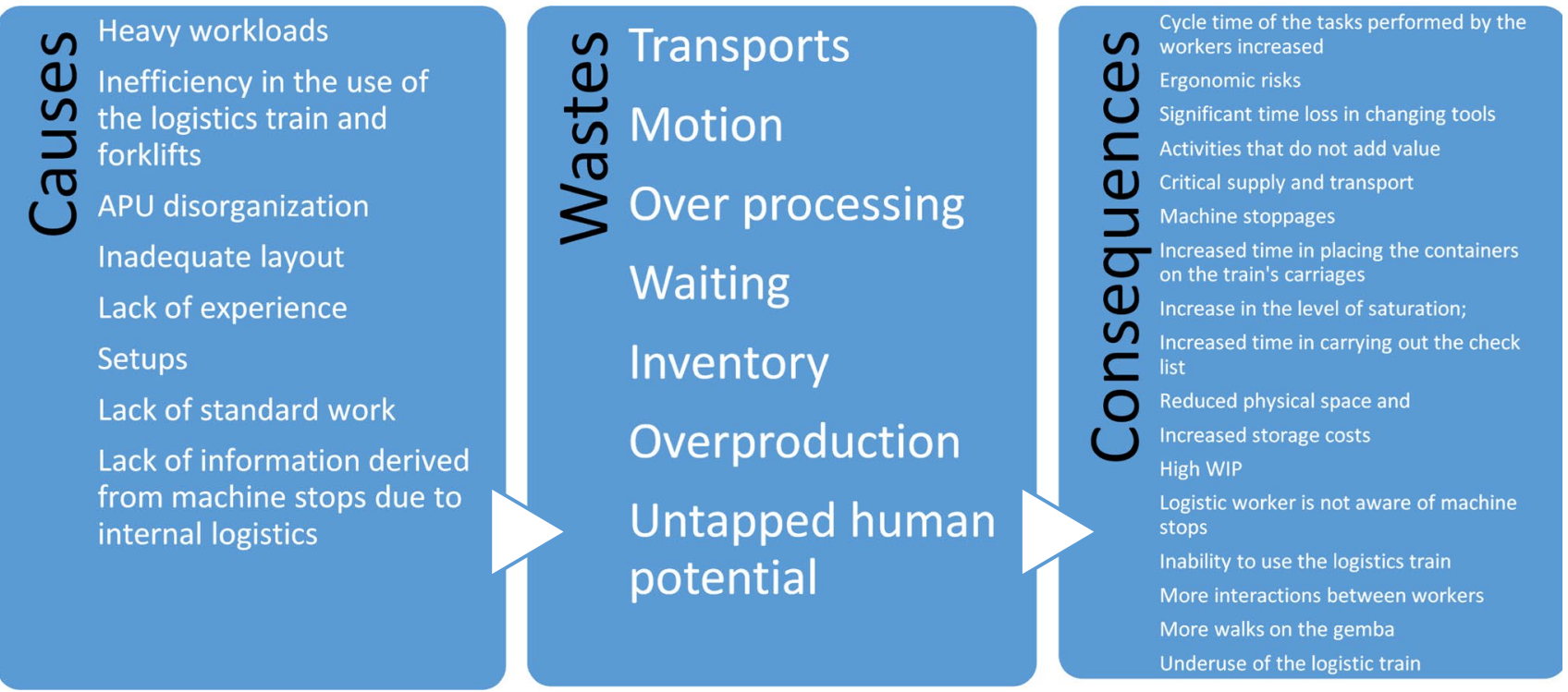

Fig. 1 Causes, wastes type and consequences of the problems identified

throughout the study, had an impact on interactions between workers within the organization, which must be reduced.

\section{Improvement Proposals}

This section presents the improvement proposals and the concepts were they based on to solve the problems described. Throughout the project, improvement actions were proposed and some were implemented. Attending to the third question that guided the study "How to avoid and/or reduce the interaction between the workers?", the authors decided to focus in this paper the proposal most related with this question. The proposal is associated with the introduction of AGV in the stamp line. This introduction was studied through a simulation model. Before presenting this, the authors also explain the approaches used to develop this project.

\section{Approaches Used}

Attending to the synthesis section, the identified problems were mainly from three sources: disorganization, load handling and transport. This called for an integrated approach of three key concepts: Lean, Logistics and Ergonomics. Figure 2 shows the integration of the areas and the synergies between the three concepts, supported by a 3D simulation, using the Simio software.

Thus, the aims were to eliminate the inappropriate tasks from the point of view of ergonomics and improve the work

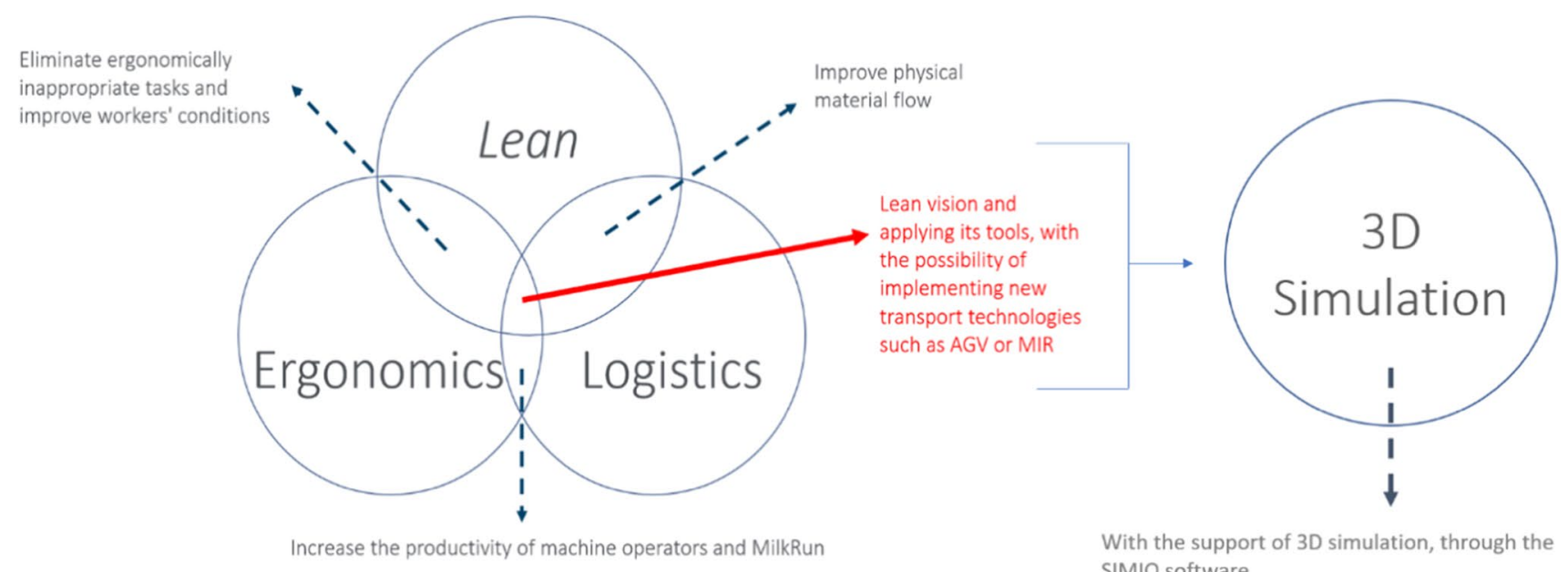

SIMIO software.

Fig. 2 Integration of the areas and the synergies between Lean, Logistics and Ergonomics, supported by 3D simulation 
conditions; reduce human interactions in tasks; improve the physical flow of materials within the autonomous production unit, and increase the productivity of workers, in this case in the M1 and M2 machines. This could be achieved by the combination of the principles of Lean and ergonomics, by implementing improvement actions to reduce effort and workload: redesign of work benches, visual management for the standardization of the picking of parts by the production workers, implementation of a exoskeleton for the tasks developed by the production worker, incorporation of labor gymnastics practices, implementation of a motorized vehicle to push/pull the containers, among others.

The combination of the ergonomic principles with Lean Logistics allowed to increase the productivity of both workers. Improvements at the ergonomic level conducted to better working conditions to carry out the tasks, and therefore, to a better performance.

The application of Lean principles in the internal logistics of the organization, allowed the improvement of the physical flow of materials and, thus, the internal value chain of the organization, allocating the containers near the machines in the correct time and in the right number.

Finally, by combining these three key concepts, some improvements were made at the ergonomic and logistical level, based on the Lean principles, with the possibility of implementing new workload and transport technologies associated with I4.0, Thus, it was intended to achieve these objectives by proposing an exoskeleton, already referred, for the heavy workload, and an autonomous Automated Guided Vehicle (AGV) or a Mobile Industrial Robot (MIR). They are even more essential in a pandemic scenario due of not being necessary a worker to guide them. In this paper, particular attention is given to the AGV integration proposal. For this study, it was used 3D simulation using SIMIO software (Vieira et al. 2014).

\section{AGV Study}

After the implementation of several proposals for improvements, it was found that they improved the conditions of the logistics workers, but they were unable to reach the machines in time to leave the empty containers and collect the full containers. In this way, other improvements for the reduction of supply time and elimination of machine stops due to the exchange of references, were proposed. One of them was the project to integrate AGV. With the AGV, the intention was to improve the materials flow as well as the working conditions of the operators, by reducing the occurrence of musculoskeletal injuries and reducing the interaction of workers in the shop floor. The introducing of AGV is a high investment, so it was necessary to be very well thought, analyzed, and justified. The following sections present this study.
Study of Physical Space and Possible Modifications The existent situation had a route made by the logistic train that did not provide a good use of the milk run, and caused the problems identified associated with internal logistics. Figure $3 \mathrm{a}$ shows that route. At first, the intention was to implement AGV exclusively in APU2, the APU under study, represented in Fig. 3b. Nevertheless, it was necessary to validate the viability of this solution. For this, a 3D simulation was developed.

Before implementing the AGVs, it was essential to understand the context of the physical space for them, through the measurements made. The central corridor had a width of 4.05 meters. The width of the corridor where the presses were installed was about $3 \mathrm{~m}$ (Fig. 4a). Thus, the implemented AGVs must fit into the current physical space of APU2. In addition, it was necessary to study whether one or more AGVs should go to the M1 and M2 presses, knowing that the task would be to take the empty containers close to the machines and collect the containers full of parts produced to allocate them in the Start zone or in the WIP warehouse (Fig. 4b).

Thus, it was necessary to organize the physical space in the allocation zone of containers filled with final products in the start area (Fig. 5a) of the WIP supermarket. Figure 5b shows the augmented buffer WIP area with the input and output points.

AGV Alternatives Studied Automated Guided Vehicle (AGV) is an autonomous and self-guided mobile vehicle used in environments that transport products, containers and pallets. It is programmed to transport materials through defined paths. They emerged as an alternative to the classic solution of having forklifts and forklift drivers transporting raw materials and products on the shop floor (Freitas et al., 2017).

The AGV selection implied to study various criteria, namely: the ease of programming/software, navigation system, its adaptation to the existing physical space and the rolling bases found in the autonomous production unit, the level of accuracy required, the safety, the preference of the type of AGV, energy consumption, the capacity of transported and autonomously carried loads and the maintenance cost.

It was decided that the suitable AGVs should have: a programming facility and software that is easy to be incorporated and understood before being used; the level of accuracy must be adapted depending on the type of cargo that in this case were containers, weighing between $750 \mathrm{~kg}$ and $1200 \mathrm{~kg}$, incorporated into the rolling carriers; the AGV should transport significant loads, which can be by itself, on platform or requester, which allows to understand how the AGV can take the empty containers and collect the full containers. Therefore, two types of AGV for the transporting of unit loads were identified: the AGV requester adjustable 


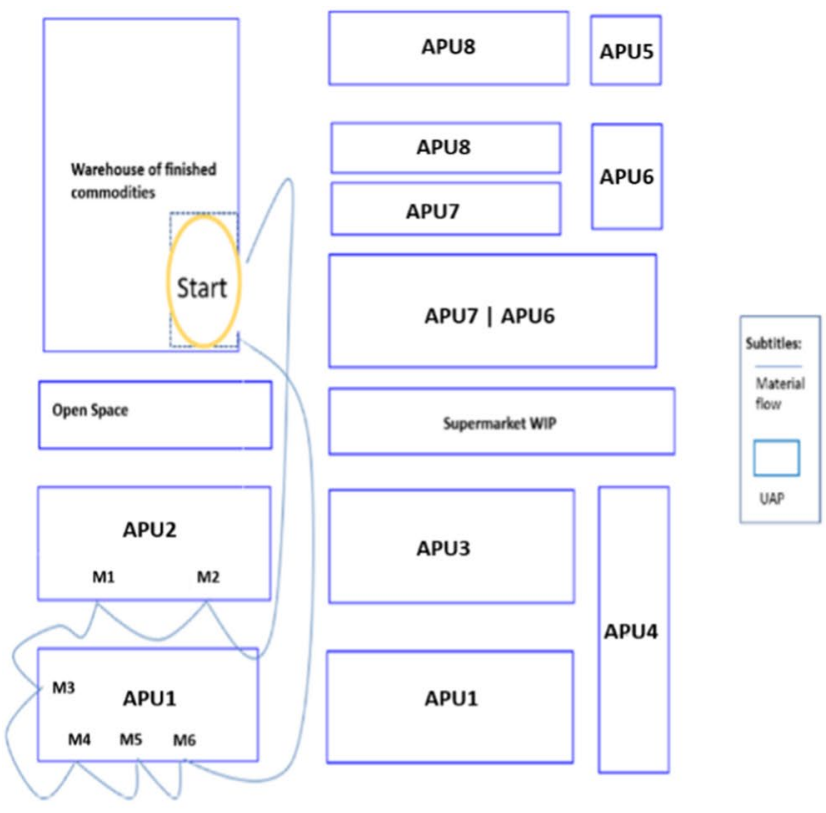

(a)

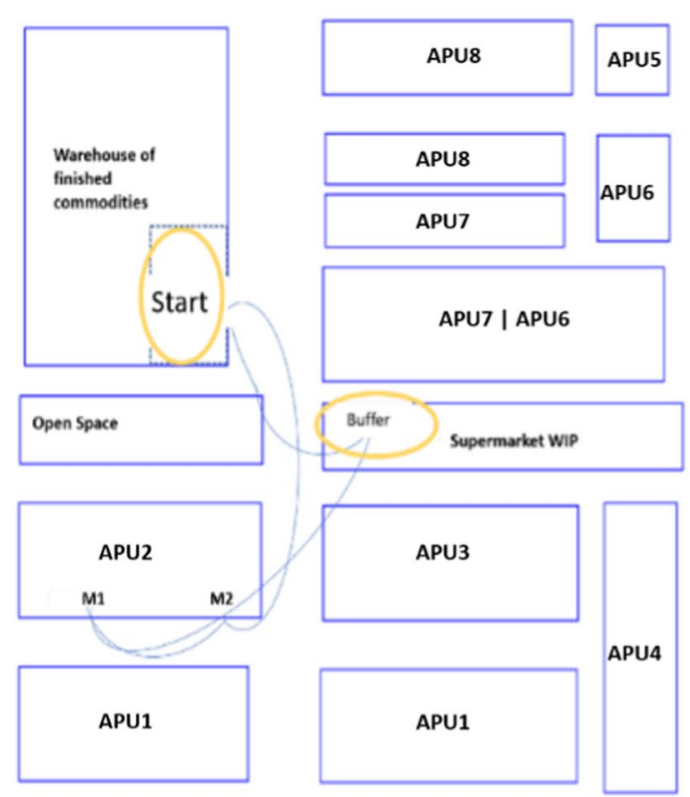

(b)

Fig. 3 Routes: a Milk run; b AGV

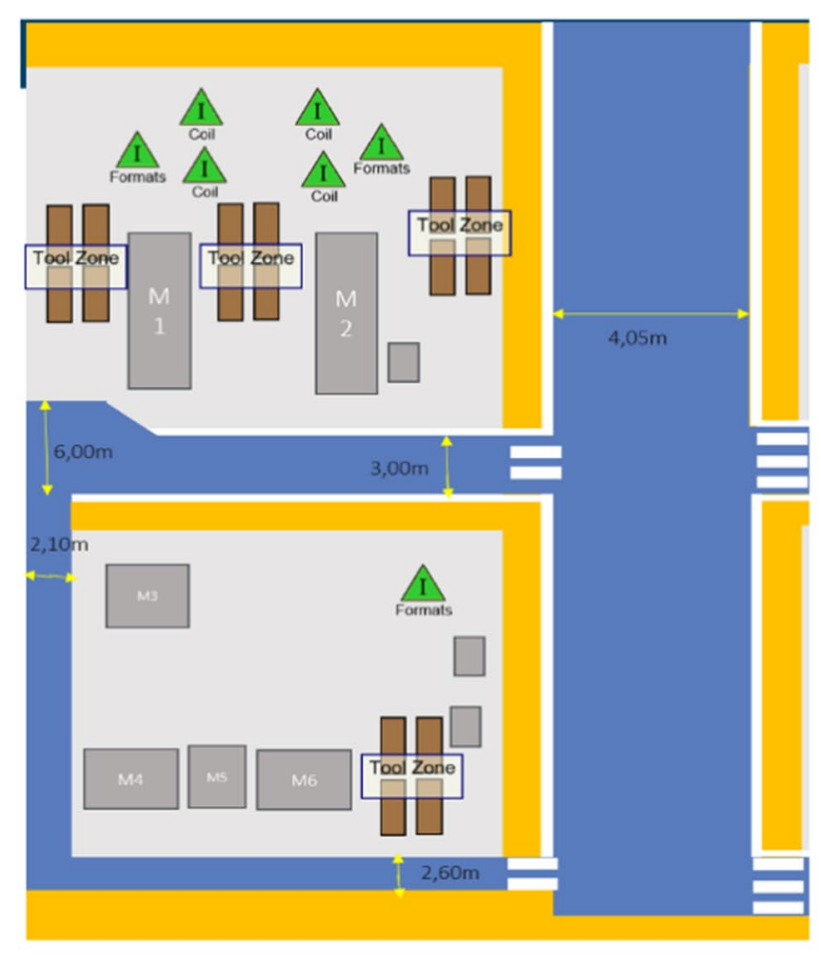

(a)

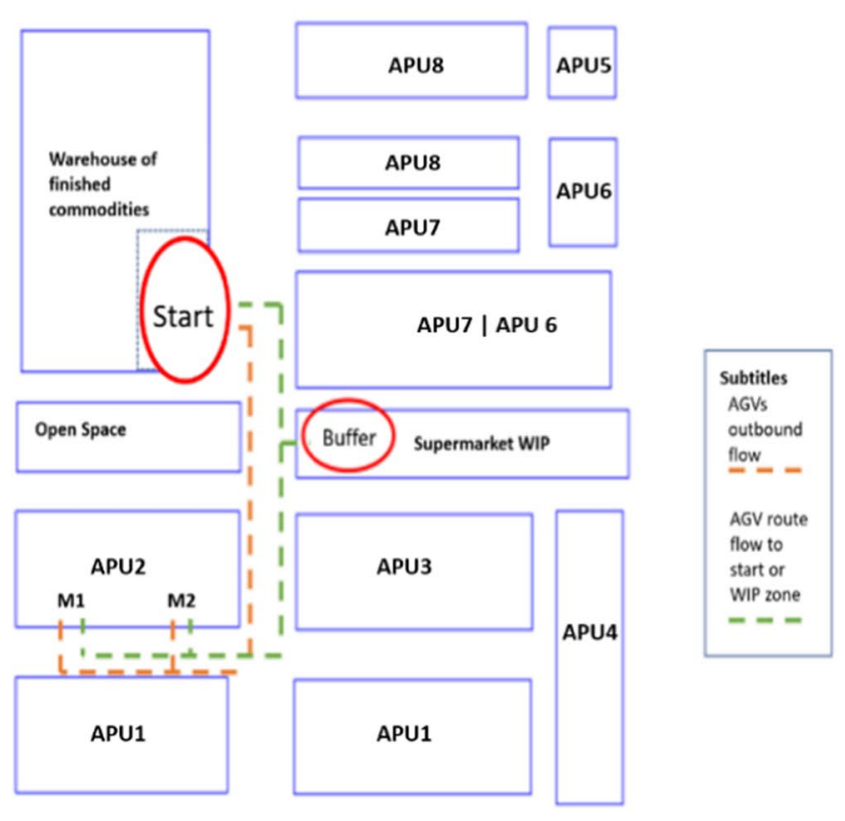

(b)

Fig. 4 Layout of APU2: a corridor measurements, $\mathbf{b}$ route of AGV for the material flow 
to the type support and AGV of lift or load platform that automatically carry itself the load, i.e., the load pass from the machines or shelves to the AGV (Fig. 6).

It was also intended to have an AGV adaptable to all types of rolling supports as can be seen in the Fig. 7, and the AGV should have a specific label reader to identify what type of parts was transporting and where it would have to be allocated. Subsequently, if the project was approved, a bespoke AGV could be developed, suitable for the problems encountered and responding to the main objectives.
From the established criteria, ten potential AGV standards were selected that met the main objective stipulated (Fig. 8).

To choose the best alternative for the project, it was used the Analytic Hierarchy Process (AHP) methodology (Martins, Sousa \& Barros, 2009; Saaty, 2000). The alternative pointed out by the AHP was the alternative E. This model could be programmed to be autonomous, without the need to have the logistic worker. Nevertheless, design

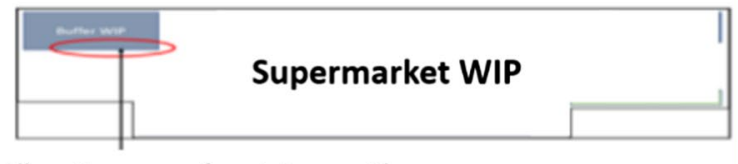

Allocation zone of containers with parts in the process of manufacture, allocated by AGV

\section{WIP containers already in the Buffer Buffer WIP}
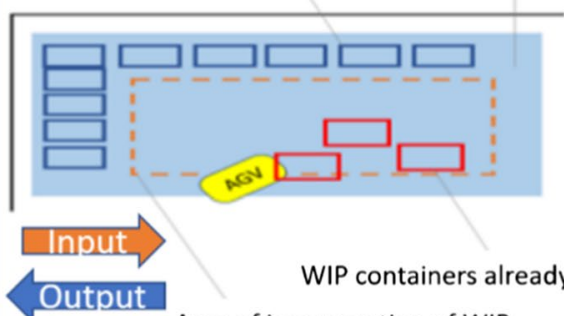

WIP containers already in the Buffer

Area of incorporation of WIP containers by AGV

(b)

Fig. 5 Implementation zone for unloading AGV WIP containers: a layout of the WIP supermarket; b WIP buffer layout inside the supermarket allocation zone
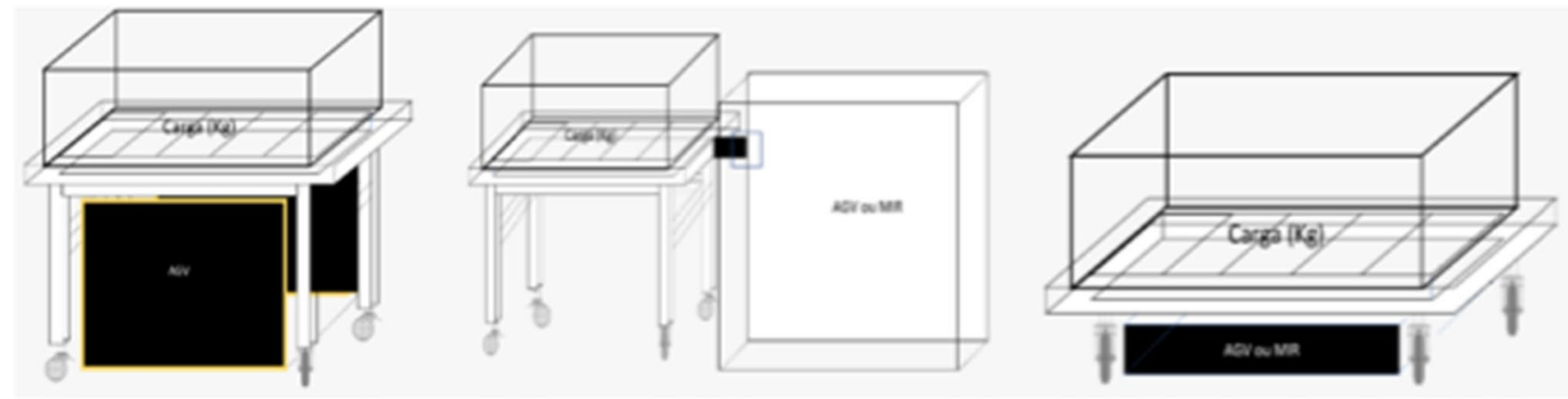

Fig. 6 Type of AGVs (3D representation)

Fig. 7 Types of rolling supports (big and small containers)
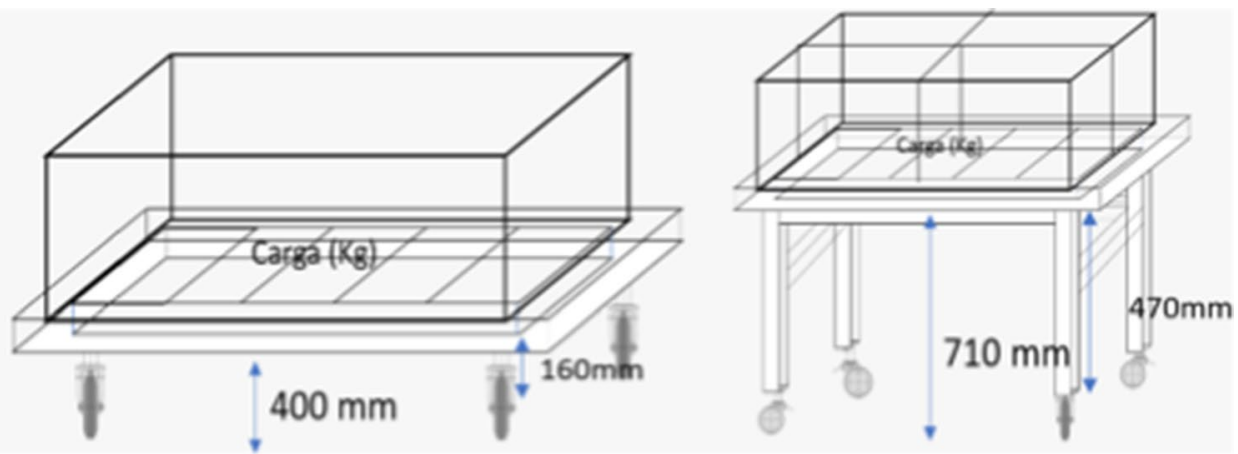


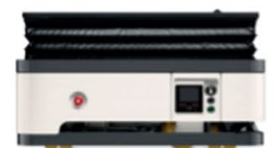

Alternative: $A$ Information: E: Asti M AGV: Quabot 2000

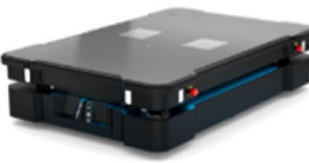

Alternative: $B$ Information: E: Minuteman/EmpireAutomotion M_AGV: MIR1000

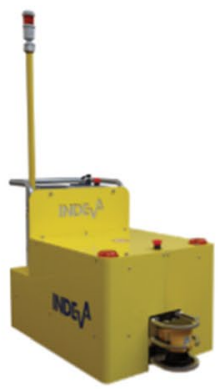

Alternative: $\mathrm{C}$ Information:

E: Indeva Grupo M_AGV: INDEVA TUGGER AGV

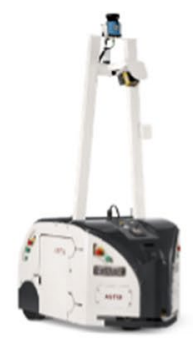

Alternative: D

Information:

E: Asti

M_AGV: Tribot 3T

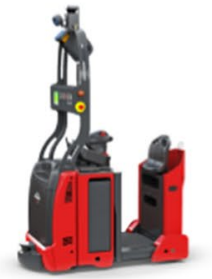

Alternative: $\mathrm{E}$ Information: $E$ : Linde M_AGV: P-MATIC

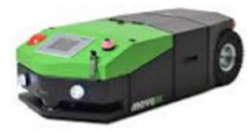

Alternative: $\mathrm{F}$ Information: E: Movexx M_AGV: AGVV1000

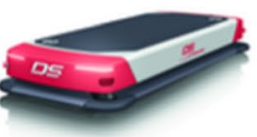

Alternative: $\mathrm{G}$

Information: E: FAW/ LogisticEngineering M_AGV: AGV Oscar OMNI

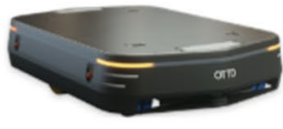

Alternative: $\mathrm{H}$ Information: E: OTTO motors M_AGV: OTTO 1500 (Load)

Alternative: I

Information: E: OTTO motors M_AGV: OTTO 1500 (Lift)

\section{Alternative: $j$ Information: E: Linde M_AGV:P-30 Towing AGV}

Fig. 8 Ten potential AGVs types for this project

Table 2 Reduction of supply time with the solution obtained though the simulation model

\begin{tabular}{llll}
\hline Machines & $\begin{array}{l}\text { Supply time with the } \\
\text { logistic train (min) }\end{array}$ & $\begin{array}{l}\text { Supply time with } \\
\text { two AGV (min) }\end{array}$ & $\begin{array}{l}\text { Reduction of } \\
\text { supply time } \\
(\%)\end{array}$ \\
\hline M1 & 32 & 16 & $50 \%$ \\
M2 & 32 & 15 & $53 \%$ \\
\hline
\end{tabular}

a customized AGV was also a possibility that was explored but it is not detailed in this paper.

3D Simulation Model and Results After the selection of an AGV type, it was necessary to create a 3D simulation model of the layout to determine how many AGVs the company will need to satisfy the materials workload and transport and the best routes to reduce wastes. After collecting the data needed, e.g., machines times, handling and transport times and define the tasks to be carried by the AGV, it was defined the running and warm-up time and the number of iterations for the model. With the model, it was also studied the transport using the logistic train against the AGVs (one or two). The 3D simulation model is described elsewhere (Afonso et al., 2021).

The best solution given the simulation model was to have two AGVs. The impacts on the supply time are in
Table 2. It is possible to see a decrease of about $50 \%$ for both machines (M1 and M2).

This parameter is essential in the decision to implement the solution, in addition to the benefits in terms of route time (reduced almost 40\%) and cost reduction and environmental improvements.

Result of the Feasibility of AGVs' Introduction As referred above, AGV introduction implies a high investment. Thus, it was necessary to evaluate the costs involved and compared these with the existent solution (logistic and forklift). After considering the costs of acquisition of the two AGVs, energy and maintenance costs, AGV implementation would bring savings of around $14 \%$ in the first year, being predicted higher savings in the following years. Labor costs were not considered as the AGVs are autonomous. This could have another advantage, the one of reduction of the irregularity in the routes because, even with a logistic train that supposedly follow a fixed and pre-established route, the human operator could disobey the route.

It was also important to evaluate the environmental performance of the two AGVs. At the environmental level, this solution allows to reduce energy consumption costs by around $3 \%$ and $\mathrm{CO}_{2}$ emissions by around $58 \%$. 
Discussion on the AGV Introduction and Simulation in a Pandemic Context The introduction of AGVs was proposed and it viability confirmed with economic and environmental benefits. However, the AGVs acquisition process was interrupted due to the economic crisis stemming from the pandemic that caused some moderation of the company in investments in assets. Nevertheless, the AGV introduction would be beneficial in the context of pandemic situation.

Answering to third question of how to avoid and/or reduce the interaction between the workers and in the shop floor, in this study, two different strategies with different purposes were used: AGV use and simulation. AGV being autonomous do not need a logistic operator. In this way, AGVs could replace human operators in handling heavy loads, making them available to perform more complex and less repetitive tasks. In addition, it would provide automation of internal logistics tasks and ensure efficient, safe and more accessible cargo transportation by reducing the interaction between workers. At the same time, reduce labor costs, which would mean a high probability of having returns quickly. Of course, it is just a small step but it is a beginning.

Using a simulation model to study the production system, the industrial engineers do not need to be all the time in the gemba (shop floor). Thus, movements, motion and interactions between workers within the company were limited.

\section{Managerial Implications}

Managerial implications are that companies must be more pragmatic and must anticipate unexpected events using, not an isolated approach, but some synergetic approaches like Lean, Logistics and Ergonomics, that were used in this project to eliminate work overload (muri), irregularity (mura), and waste (muda). According to the problems and wastes identified, others could be chosen and combined. This project proved that, with this synergetic triad in mind, actions were proposed that were suitable for a normal but also a pandemic situation. This answered to fourth question raised in the introduction. Lean, Logistics and Ergonomics are, indeed, suitable to prepare shop floor work systems to face pandemic situations. Synergistically approached they also point out other methodologies and strategies to adopt to solve the problems identified, as in this case, pointing out technologies such as AGV.

This project also proved that the current and the future factories, must prepare the shop floor system, by looking for opportunities to automate, in an intelligent way, the production processes. This will provide smoothed logistics processes and limited interactions between workers.

In addition to the notable changes and an adaptation of the companies from the technological point of view, to overcome the health crisis, standardize some processes within organizations, to improve the space plant utilization and provide less human interaction within manufacturing processes. Those changes could also be achieved through $5 \mathrm{~S}$ and visual management that delimits circulation zones and spaces (this was not explored in this paper). Those approaches are valid in both the pandemic and post-pandemic situations and provide a paradigm shift by companies.

Nevertheless, all changes should be studied and its impact in environmental evaluated. It is not desirable to introduce technologies that negatively impact the environment. When Lean Thinking becomes a culture this will not happen. Lean Thinking is a pursuer of global and sustainable development using the technologies and tools existent (e.g., as the ones from I4.0) or to be created (Alves et al., 2019a, 2019b).

During this investigation, several limitations related to management decisions arose, notably, the financial pull back for the possible implementation of AGVs due to the pandemic situation. In addition, the resistance to change from the organization's workers is also an important aspect that companies must be alert for it.

\section{Concluding Remarks}

The project discussed in this article allows to understand that, to implement automation systems for logistical processes, various aspects must be studied. First, it was important to identify the wastes and their root causes. One particular waste was the one related to ergonomic conditions, this means that it was necessary to analyze the ergonomic risk. Then, attended to the crisis of global COVID-19, impacting large and small economies and hampering the growing economic evolution of several countries, it was important to: (1) provide a healthier environment to workers by reducing their interaction in the shop floor; (2) integrate different approaches and multidisciplinary views. In this particular case, the authors used the synergy provided by the triad: Lean, Logistics and Ergonomics. Feasibility studies followed the solutions proposed, also using different methodologies and tools.

The main contributions of this paper were to highlight that companies, based on the real needs they have, must take into account the importance of automation and new technologies associated with industry 4.0 , to achieve high levels of operational effectiveness. Moreover, when facing a pandemic situation, a shop floor more automated provides an advantage and a safer workplace for people as it limits operator interactions within organizations.

Limitations of this study are related to the qualitative nature of the research methodology. This means that results cannot be generalized. In addition, all observations, analyses and results were from an individual interpretation and perspective (the researcher in the workplace). 
For future work, and with the help of government support packages, the company expects to acquire and implement $\mathrm{AGV}$ and other technologies to reduce human interactions in shop floor systems (for example, RFID). More specifically, with regard to this research may be mentioned various aspects, particularly the study of automating logistics processes in all stamping lines throughout the organization.

\section{Key Questions Reflecting Applicability in Real Life}

1. What is the significance of advanced technologies such as automation in the Industry 4.0 driven competitions? What are the major factors firms must consider while adopting advanced manufacturing technologies and systems?

2. How to develop company-specific resilient shop floor operations in the post-pandemic rebound to operational excellence?

3. How to leverage the work floor conditions of your company towards competitiveness?

4. What is the proper mindset that companies must embed to achieve a sustainable business?

Acknowledgements The authors acknowledge the reviewers and the Editor-in-Chief for their revisions and comments that allowed the improvement of the quality of the paper. Also, the authors would like to acknowledge the company where the study was developed.

\section{where the study was developed}

Author contributions TA: data collection; company study and analysis; proposals presentation and implementation; writing-original draft. ACA: supervision; company study revision; review and editing, PC: supervision, company study revision; review and editing.

Funding This work has been supported by FCT-Fundação para a Ciência e Tecnologia within the R\&D Units Project Scope: UIDB/00319/2020.

Data availability Not applicable.

\section{Declarations}

Conflict of Interest The authors declare that they have no conflict of interest.

\section{References}

Abdirad, M., \& Krishnan, K. (2020). Industry 4.0 in Logistics and Supply Chain Management: A Systematic Literature Review. Engineering Management Journal, 1-15. https://doi.org/10.1080/ 10429247.2020.1783935

Afonso, T., Alves, A. C., Carneiro, P. \& Vieira, A. (2021). Simulation pulled by the need to reduce wastes and human effort in an intralogistics project. International Journal of Industrial Engineering and Management, Submitted.

AICEP (2020). Portugal Global. Portugal Global, 12-23.

Alves, A. C., Kahlen, F.-J., Flumerfelt, S., \& Siriban-Manalang, A. B. (2019a). Lean Engineering for Global Development (A. C. Alves, F.-J. Kahlen, S. Flumerfelt, \& A. B. Siriban-Manalang (eds.)). Springer

Alves, A. C., Ferreira, A. C., Costa Maia, L., P. Leão, C., \& Carneiro, P. (2019b). A symbiotic relationship between Lean Production and Ergonomics: insights from Industrial Engineering final year projects. International Journal of Industrial Engineering and Management, 10(4), 243-256. https://doi.org/10.24867/ IJIEM-2019-4-244

Arezes, P. M., Dinis-Carvalho, J., \& Alves, A. C. (2015). Workplace ergonomics in lean production environments: a literature review. Work, 52(1), 57-70.

Barroso, M., Carneiro, P., and Braga, A, C. (2006). Assessment of the risk of Musculoskeletal disorders on Dentist' activities, in the proceedings of the 16th Congress of the International Ergonomics Association (IEA). Meeting Diversity in Ergonomics, Maastricht. The Netherlands. p. 6.

Bittencourt, V., Alves, A. C., \& Leão, C. P. (2019). Lean Thinking contributions for Industry 4.0: a Systematic Literature Review. In: 9th IFAC Conference on Manufacturing Modelling, Management and Control, (2018).

Bittencourt, V. L., Alves, A. C., \& Leão, C. P. (2020). Industry 4.0 triggered by Lean Thinking: insights from a systematic literature review. International Journal of Production Research, 59 (5), 1496-1510. https://doi.org/10.1080/00207543.2020.18322 74

Brito, M. F., Ramos, A. L., Carneiro, P., \& Gonçalves, M. A. (2019). Ergonomic Analysis in Lean Manufacturing and Industry 4.0-A Systematic Review. In A. C. Alves, S. Flumerfelt, A B. Siriban-Manalang, \& F.-J. Kahlen (Eds.), Lean Engineering for Global Development (pp. 95-127). Springer International Publishing. https://doi.org/10.1007/978-3-030-13515-7_4

Coimbra, E. (2009). Total Flow Management: achieving excellence with Kaizen and Lean Supply Chains. Kaizen Institute.

de Mattos, D. L., Teixeira, L. A. F., Merino, E. A. D., \& da Silva Júnior, O. F. P. (2016). Ergonomics Quick Kaizen: a case study in an auto industry. Journal of Lean Systems, 1(3), 69-78.

Deshumukh, S. G., \& Haleem, A. (2020). Framework for manufacturing in post-COVID-19 world order: an Indian perspective. International Journal of Global Business and Competitiveness, 15(1), 49-60. https://doi.org/10.1007/s42943-020-00009-1

Dw (2020). As a consequence of covid 19 for the world economy. Consulted on 30/12/2020 in https://www.dw.com/pt-002/asconsequ\%C3\%AAncias-da-covid-19-para-a-economia-mundi al/a-53021449

Flynn, B., Cantor, D., Pagell, M., Dooley, K., \& Azadegan, A. (2020). Managing Supply Chains Beyond Covid-19: Preparing for the Next Global Mega-Disruption. Journal of Supply Chain Management, jscm.12254. https://doi.org/10.1111/jscm.12254

Freitas, A. C., Maio, A. F., Maia, P., Gomes, N., Nogueira, A., Fernandes, J. M., Carvalho, M. S., Alves, A. C., Costa, A., Afonso, P., Silva, P. V, Barbosa, D., \& Machado, S. (2017). Savings in internal logistics using a RFID-based software system in a lean context. In: Proceedings of International Conference on Computers and Industrial Engineering, CIE.

IEA (2021). International Ergonomics Association. Consulted on 28/12/2019, in https://iea.cc/WHATS/

INEE (2020). Industrial production statistics 2019. Estatisticas oficiais. Edição 2020

Ivanov, D., \& Dolgui, A. (2020). Viability of intertwined supply networks: extending the supply chain resilience angles towards survivability. A position paper motivated by COVID-19 outbreak. 
International Journal of Production Research, 58(10), 29042915. https://doi.org/10.1080/00207543.2020.1750727

Kaasinen, E., Schmalfuß, F., Özturk, C., Aromaa, S., Boubekeur, M., Heilala, J., Heikkilä, P., Kuula, T., Liinasuo, M., Mach, S., Mehta, R., Petäjä, E., \& Walter, T. (2020). Empowering and engaging industrial workers with Operator 4.0 solutions. Computers \& Industrial Engineering, 139, 105678. https://doi.org/10.1016/j. cie.2019.01.052

Kagermann, H., Wahlster, W., \& Helbig, J. (2013). Recommendations for Implementing the Strategic Initiative INDUSTRIE 4.0.

Kolberg, D., \& Zühlke, D. (2015). Lean Automation enabled by Industry 4.0 Technologies. IFAC-PapersOnLine, 48(3), 1870-1875. https://doi.org/10.1016/j.ifacol.2015.06.359

Liker, J. (2004). The Toyota Way: 14 management principles from the world's greatest manufacturer. $1^{\text {a }}$ Edição. New York: McGraw-Hill.

Liker, J. K., \& Morgan, J. M. (2006). The Toyota way in services: The case of lean product development. The Academy of Management Perspectives, 20(2), 5-20.

Malik, A. A., \& Brem, A. (2021). Digital twins for collaborative robots: A case study in human-robot interaction. Robotics and ComputerIntegrated Manufacturing, 68. https://doi.org/10.1016/j.rcim. 2020.102092

Martins, C., Sousa, D., \& Barros, M. (2009). O uso do método de análise hierárquica (AHP) na tomada de decisão gerenciaisUm estudo de caso. XLI SBPO 2009-Pesquisa Operacional na Gestão do Conhecimento. p. 1778-1788

Mayr, A., Weigelt, M., Kühl, A., Grimm, S., Erll, A., Potzel, M., \& Franke, J. (2018). Lean 4.0-A conceptual conjunction of lean management and Industry 4.0. Procedia CIRP, 72(May), 622-628. https://doi.org/10.1016/j.procir.2018.03.292

Melo, T., Alves, A.C., Lopes, I., \& Colim, A. (2020). Reducing 3M by Improved Layouts and Ergonomic Intervention in a Lean Journey in a Cork Company. In A. P. et al. (eds) (Ed.), Occupational and Environmental Safety and Health II. Studies in Systems, Decision and Control (pp. 537-545). https://doi.org/10.1007/978-3-03041486-3_58

Monden, Y. (1998). Toyota production system: an integrated approach to just-in-time. Georgia, Engineering \& Management Press.

Mrugalska, B., \& Wyrwicka, M. K. (2017). Towards lean production in industry 4.0. Procedia Engineering, 182, 466-473.

O'Brien, R. (1998). An overview of the methodological approach of action Research. University of Toronto, 1-15. http://www.web.ca/ robrien/papers/arfinal.html.

Ohno, T. (1988). Toyota production system: beyond large-scale production. Productivity Press. https://doi.org/10.1108/eb054703

De Oliveira, R. P., Stefenon, S. F., Branco, N. W., De Oliveira, J. R., \& Rohloff, R. C. (2017). Lean manufacturing in association with industrial automation: Case study applied to the furniture industry.Espacios, 38(17).
Oztemel, E., \& Gursev, S. (2020). Literature review of Industry 4.0 and related technologies. Journal of Intelligent Manufacturing, 31(1), 127-182. https://doi.org/10.1007/s10845-018-1433-8

Romero, D., Bernus, P., Noran, O., Stahre, J., \& Fast-Berglund, Å. (2016). The Operator 4.0: Human Cyber-Physical Systems \& Adaptive Automation towards Human-Automation Symbiosis Work Systems. APMS (Advances in Production Management Systems).

Romero, D., Stahre, J., Wuest, T., Noran, O., Bernus, P., Fast-Berglund, A., \& Gorecky, D. (2016). Towards an Operator 4.0 typology: a human-centric perspective on the Fourth Industrial Revolution technologies. CIE46 Proceedings, 29-31 October 2016, Tianjin / China.

Romero, D., Stahre, J., \& Taisch, M. (2020). The operator 4.0: towards socially sustainable factories of the future. Computers \& Industrial Engineering, 139, 106128. https://doi.org/10.1016/j.cie.2019. 106128

Saaty, T. L. (2000). Decision making for leaders. WS. Publications.

Spear, S., \& Bowen, H. K. (1999). Decoding the DNA of the Toyota production system. Harvard Business Review, 77(5), 96-106.

Tortorella, G. L., \& Fettermann, D. (2018). Implementation of Industry 4.0 and lean production in Brazilian manufacturing companies. International Journal of Production Research, 56(8), 2975-2987. https://doi.org/10.1080/00207543.2017.1391420

Tortorella, G. L., Rossini, M., Costa, F., Portioli Staudacher, A., \& Sawhney, R. (2019). A comparison on Industry 4.0 and lean production between manufacturers from emerging and developed economies. Total Quality Management \& Business Excellence, 1-22. https://doi.org/10.1080/14783363.2019.1696184

Valamede, L. S., \& Akkari, A. C. S. (2020). Lean 4.0: a new holistic approach for the integration of lean manufacturing tools and digital technologies. International Journal of Mathematical, Engineering and Management Sciences, 5(5), 851-868. https://doi. org/10.33889/IJMEMS.2020.5.5.066

Vieira, A., Dias, L., Pereira, G. \& Oliveira, J. (2014). Comparison of Simio and Arena simulation tools. In: 12th Annual Industrial Conference, ISC 2014.

Waschull, S., Bokhorst, J. A. C., Molleman, E., \& Wortmann, J. C. (2020). Work design in future industrial production: transforming towards cyber-physical systems. Computers \& Industrial Engineering, 139, 105679. https://doi.org/10.1016/j.cie.2019.01.053

Womack, J., and Jones, D. (1996). Lean thinking_-banish waste and create wealth in your corporation. Simons \& Schuster.

Womack, J., Jones, D., \& Roos, D. (1990). The machine that changed the world: the story of lean production. Rawson Associates. 


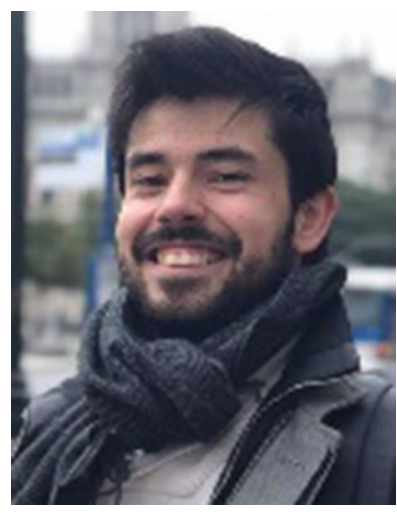

Tiago Afonso currently works as a project engineer at a consulting company, working on projects in the automotive area. After completing his master's degree in industrial engineering at the University of Minho, Portugal, he began his career in the field of continuous improvement in the automotive industry, a company that manufactures metal parts for vehicles. He is the author of one publication and two other publications in the process of acceptance.

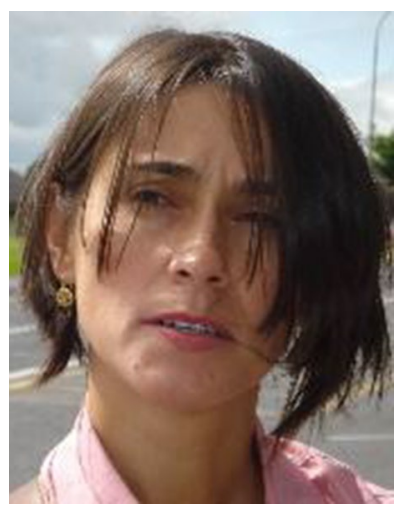

Anabela C. Alves is Assistant Professor at the Department of Production and Systems Engineering of the University of Minho (UM) and affiliated on ALGORITMI Centre, Portugal. She holds a $\mathrm{PhD}$ in Production and Systems Engineering. Her main research interests are in the areas of Production Systems Design and Operation; Lean Production and Lean Education; Production Planning and Control, and Engineering Education. She is author/coauthor of more than 200 publications. She supervised $2 \mathrm{PhD}$ and is supervising $5 \mathrm{PhD}$ and supervised more than 100 Master dissertations in Industrial Engineering and Management
(IEM). She is member of the Scientific and Organizing Committee of the International Symposium on Project Approaches in Engineering Education (PAEE), (http://paee.dps.uminho.pt). She was involved in 3 and currently in 1 financed projects with industry. ORCID: http://orcid. org/0000-0002-2926-4187.

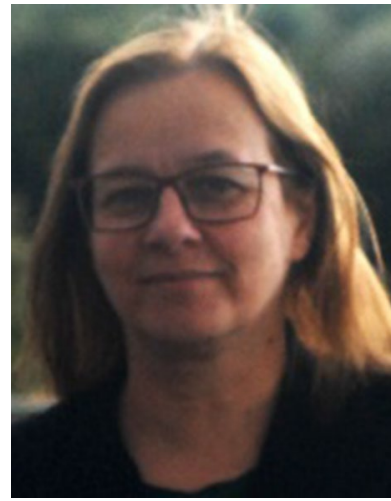

Paula Carneiro is Assistant Professor at the Department of Production and Systems Engineering (University of Minho), and affiliated on ALGORITMI Centre (Ergonomics \& Human Factors Research Group). She holds a PhD in Industrial and Systems Engineering. She authored/coauthored more than 50 indexed scientific publications. She supervised $2 \mathrm{PhD}$ and currently is supervising $1 \mathrm{PhD}$. She is member of the Organizing Committee of the International Symposium on Occupational Safety and Hygiene since 2008. Since May 2015, she is the Coordinator of the Master's course in Human Engineering. She has been/is coordinator/ member of externally funded research projects in the domains of Ergonomics, Occupational Safety and Hygiene. ORCID: https://orcid. org/0000-0003-0874-8593. 